\title{
STRATEGI PENGGUNAAN MEDIA SOSIAL SAUNG ANGKLUNG UDJO DALAM MENGKOMUNIKASIKAN ESTETIKA BAMBU
}

\author{
Rah UtamiNugrahani ${ }^{1)}$, Sylvie Nurfebiaraning ${ }^{2)}$ \\ ${ }^{1}$ Fakultas Komunikasi dan Bisnis, Telkom University \\ nugrahani.rahutami@gmail.com \\ ${ }^{2}$ Fakultas Komunikasi dan Bisnis, Telkom University \\ sylvienurfebia@gmail.com
}

\begin{abstract}
Saung Angklung Udjo (SAU) is a performance venue that was founded in 1966 by UdjoNgalagena and has stood until now for one of them aimed at communicating bamboo music, in this case focusing a lot on angklung, as Indonesia's cultural wealth, especially West Java. To further develop themselves, SAU also began to move in the online field, which in this case was specifically done through social media, especially Youtube and Instagram. To find out more about SAU's social media strategy in communicating SAU's aesthetics, observations, interviews and literature studies were conducted. After taking the data which is then processed by qualitative methods, the following results and discussion are obtained: SAU conducts all publications and documentation related to on-site performances to be uploaded via Instagram and Youtube, SAU collaborates to increase the popularity of bamboo music, with one of them picking up composer Eka Gustiwana is able to produce fresh works that are accessible to the public, SAU re-arranged to make bamboo music familiar, especially among Western music listeners, and this strategy is also generally a form of angklung preservation in its position as Intangible Cultural Heritage of Humanity by UNESCO version which was passed in 2010.
\end{abstract}

Keywords: Saung Angklung Udjo, media sosial, estetika bambu.

\section{PENDAHULUAN}

Saung Angklung Udjo (SAU) adalah suatu tempat di wilayah Bandung, Jawa Barat, yang merupakan tempat pertunjukan, pusat kerajinan tangan dari bambu, dan tempat lokakarya instrument music dari bambu. SAU didirikan tahun 1966 oleh Udjo Ngalagena dan istrinya, Uum Sumiati, dengan maksud untuk melestarikan dan memelihara seni dan kebudayaan tradisional Sunda.

Dalam perjalanannya yang sudah lebih dari lima puluh tahun, SAU telah berkembang menjadi salah satu destinasi penting di Kota Bandung, yang disasar oleh wisatawan lokal maupun mancanegara. Pertunjukkan rutin digelar setiap sore dan hampir selalu dipenuhi pengunjung, hingga akhirnya SAU mengadakan pertunjukkan khusus yang dilakukan pada pagi atau siang hari.

Atas dasar itu, SAU mulai mengem-bangkan diri, baik secara luring maupun daring. Secara luring, SAU membuka satu kawasan di wilayah Cijaringao, Kabupaten Bandung, untuk dijadikan satu kawasan reservoir berbasis lingkungan pohon bambu. Tempat yang diberi nama Cijaringao Eco Land tersebut juga bisa dijadikan objek wisata ataupun lokasi pertunjukkan.
Sementara itu, dari segi daring, SAU juga secara bertahap mulai menggarapnya secara serius. Kombinasi dari kedua media promosi tersebut dilakukan kemungkinan tidak hanya demi menarik minat turis secara lebih luas saja, melainkan juga demi mengkomunikasikan estetika bambu pada banyak khalayak. Estetika bamboo ini termasuk diantaranya musik bambu, yang tidak hanya terbatas pada angklung saja, melainkan juga calung, suling, karinding, basek, genggong, arumba, dan sebagainya. Selain itu, yang tergolong pada estetika bambu juga bisa dalam bentuk penataan bamboo dalam fungsi dekoratif maupun fungsi ekologis.

Diharapkan, dengan strategi pengkomunikasian yang dilakukan oleh SAU ini, bambu, dapat dipahami tidak hanya dalam konteks sebagai tanaman saja, melainkan punya fungsi kebudayaan yang sangat luas dan berfaedah. Atas dasar itu, dilakukan penelitian terkait bagaimana strategi media social Saung Angklung Udjo dalam rangka mengkomunikasikan estetika bambu, dengan tujuan untuk memperoleh referensi terkait sosialisasi kesenian dan kaitannya dengan pemanfaatan teknologi digital. 


\section{KAJIAN LITERATUR}

Kajian literatur dalam penelitian ini terkait dengan konsep-konsep yang menjadi kata kunci yaitu tentang Saung Angklung Udjo, Media Sosial, dan Estetika Bambu itu sendiri. Jika diurai, maka konsepkonsep yang digunakan adalah sebagai berikut:

\section{Saung Angklung Udjo}

Saung Angklung Udjo (SAU) adalah suatu tempat yang merupakan tempat pertunjukkan, pusat kerajinan tangan dari bambu, dan tempat lokakarya instrument music dari bambu. Selain itu, SAU mempunyai tujuan sebagai laboratorium kependidikan dan pusat belajar untuk memelihara kebudayaan Sunda, khususnya angklung. SAU didirikan pada tahun 1966 oleh Udjo Ngalagena dan istrinya, Uum Sumiati, dengan maksud melestarikan dan meme-lihara seni dan kebudayaan tradisional Sunda. Berlokasi di Jalan Padasuka 118, Bandung Timur, Jawa Barat, Indonesia.

Suasana lokasi SAU sendiri digambarkan memiliki udara yang segar dan dikelilingi oleh pohonpohon bambu, dari kerajinan bambu dan interior bambu sampai alat musik bambu. Di samping pertujukkan rutin setiap sore, SAU telah berkali-kali mengadakan pertunjukkan khusus yang dilakukan pada pagi atau siang hari. SAU tidak terbatas pada hanya menjual seni pertunjukkan saja, berbagai produk alat music bamboo tradisional (angklung, arumba, calung dan lainnya), dibuat dan dijual kepada para pengunjung.

\section{Media Sosial}

Media sosial adalah sebuah media daring (dalam jaringan), dengan para penggunanya bisa dengan mudah berpartisipasi, berbagai, dan menciptakan isi blog, jejaring sosial, serta forum berbasis dunia virtual. Contoh media sosial yang banyak digunakan adalah Youtube, Facebook, Blog, Twitter, Instagram, dan lain-lain. Andreas Kaplan dan Michael Haenlein mendefinisikan media sosial sebagai "sebuah kelompok aplikasi berbasis internet yang dibangun atas dasar ideology dan teknologi Web 2.0., dan memungkinkan penciptaan dan pertukaran user generated content".

Sementara itu, Philip Kotler dan Kevin Keller menyebut media social sebagai "sarana bagi konsumen untuk berbagai informasi teks, gambar, video, dan audio dengan satus ama lain dan dengan perusahaan dan sebaliknya". Menurut Marjorie Clayman, pengertian media social adalah "alat pemasaran baru yang memungkinkan untuk mengetahui pelanggan dan calon pelanggan dengan cara yang sebelumnya tidak mungkin".

\section{Estetika Bambu}

Estetika bamboo atau keindahan bamboo adalah salah satu perwujudan fungsional dari tanaman bambu yang mempunyai banyak fungsi. Selain sebagai makanan hewan, alat memasak, hingga bahan konstruksi, bambu juga punya nilai keindahan dalam aspek rupa (kerajinan dan dekorasi) dan juga sebagai bahan untuk alat music dengan suara khas.

Pertama, dari segi rupa, bamboo termasuk tanaman yang memiliki daya tahan yang cukup stabil. Sebagai salah satu tanaman yang bertumbuh paling cepat, bambu juga menarik ketika dibiarkan tumbuh secara bebas dan menghasilkan kesan acak yang justru menarik. Bambu juga dapat dibuat sebagai kerajinan seperti alas lantai, bilik, krey, dipan, pagar, hiasan dinding, hingga kipas. Kreasi yang bias dilakukan terhadap bamboo bahkan nyaris tidak terbatas.

Estetika bambu juga dapat mewujud melalui instrument musik yang berbahan dasar bambu, seperti angklung, calung, karindng, arumba, suling, dan sebagainya. Instrumen musik yang terbuat dari bamboo memiliki cirri khas dalam hal suaranya. Biasanya, suara yang dihasilkan mempunyai nuansa antara bunyi kayu dan bunyi angin.

\section{METODE PENELITIAN}

Penelitian ini menggunakan metode kualitatif dengan teknik pengumpulan data sebagai berikut:

\section{Observasi}

Observasi dilakukan terhadap aktivitas di Saung Angklung Udjo dari mulai bulan Agustus hingga Oktober 2019. Observasi dilakukan dengan cara pengamatan dan pencatatan selama jam-jam pertunjukkan $(16.00-17.30)$ selama seminggu tiga kali.

\section{Wawancara}

Wawancara dilakukan terhadap informan yang sudah dipilih berdasarkan criteria sampel purposif. Informan-informannya adalah sebagai berikut:

1. Taufik Hidayat, pemilik Saung Angklung Udjo

2. Robby Murphy, bagian Hubungan Masyarakat Saung Angklung Udjo.

3. Perwakilan warga Padasuka

4. Perwakilan grup music bamboo Babenjo.

5. Perwakilan wisatawan Saung Angklung Udjo. 


\section{Studi Literatur}

Studi literatur dilakukan dengan mengumpulkan referensi mengenai Saung Angklung Udjo dan Estetika Musik Bambu.

\section{HASIL DAN PEMBAHASAN}

Hasil dan pembahasan dalam penelitian ini terbagi ke dalam tiga bagian, yaitu hasil dan pembahasan berdasarkan observasi, wawancara, dan studi literatur.

\section{Berdasarkan Observasi}

Berdasarkan observasi yang dilakukan dari bulan Agustus 2019 hingga Oktober 2019 langsung di SAU, maka diperoleh hasil sebagai berikut:

a. Daya tarik dari SAU dibangun ber-dasarkan kombinasi dekorasi bambu dan musik bambu.

b. Kombinasi dekorasi bambu dan music bamboo tersebut diwacanakan sebagai representasi dari budaya lokal, khususnya Jawa Barat.

c. Dalam atraksi pertunjukan SAU selama kurang lebih satu setengah jam, pengalaman langsung dan interaksi menjadi kunci edukasi dan hiburan.

d. Pemanfaatan media sosial dalam hal ini lebih ditujukan pada promosi atau publikasi serta dokumentasi dari kegiatan SAU.

e. Dalam beberapa kesempatan, terdapat tim dokumentasi dari SAU yang merekam kegiatan dan ditujukan untuk perluasan publikasi lewat Instagram atau Youtube.

f. Para pengunjung diberi kebebasan dan bahkan dianjurkan untuk melakukan dokumentasi secara pribadi untuk diunggah ke media sosial.

\section{Berdasarkan Wawancara}

Berdasarkan wawancara yang dilakukan terhadap para informan yang sudah dipilih berdasarkan kriteria sampel purposif, maka diperoleh hasil sebagai berikut:

a. Taufik Hidayat, pemilik SAU, mengatakan bahwa pihaknya selalu berusaha mencari inovasi baru dalam pemanfaatan media sosial. Misalnya, menggaet composer Eka Gustiwana untuk membuat beberapa konten bersama dan diunggah keYoutube. Contoh konten misalnya berjudul "\#On My Cover dengan Kearifan Lokal (Feat: Angklung Udjo)", "Nostalgia Lagu Iklan Legendaris Part 1", "Nostalgia Lagu Iklan Legendaris Part 2", dan banyak lagi. Tiga konten di tersebut mencapai total viewers hamper enam juta. Dengan menggaet Eka Gustiwana, musik yang ditampilkan pun tetap memiliki nilai keindahan dari segi musik bambu. b. Robby Murphy, bagian Hubungan Masyarakat SAU, mengatakan bahwa Saung Angklung Udjo terus melakukan perbaharuan pada konten media sosial, terutama Instagram, agar senantiasa terlihat informative sekaligus menarik. Saluran Youtube dari SAU sendiri terus dipromosikan dan sekarang mencapai lebih dari Sembilan ribu subscribers. Konten dari baik Instagram maupun Youtube tersebut memuat umumnya pertunjuk-kan di Saung Angklung Udjo yang memanfaatkan instrument bambu.

c. Ayu (24 tahun), perwakilan warga Padasuka, menyebutkan bahwa kehadiran SAU secara umum telah memperbaiki ekonomi warga sekitarnya. la mengusulkan agar SAU dipublikasikan lebih sering agar menjadi contoh bagi tempat kesenian lain agar dapat juga punya nilai ekonomi bagi warga setempat. Artinya, media sosial jangan hanya terbatas menyoroti kegiatan di SAU saja, tapi juga dampaknya bagi warga Padasuka.

d. Maulana (43 tahun) adalah perwakilan dari grup musik Babendjo. Sementara Babendjo sendiri adalah kelompok ensembel angklung binaan SAU. Menurut Maulana, dalam setiap penampilan Babendjo sekarang ini, media sosial selalu dilibatkan sebagai media publikasi maupun dokumentasi. Selain itu, Babendjo, secara musik juga terus berinovasi dengan memainkan berbagai komposisi dari mulai komposisi lokal, nasional, hingga mancanegara seperti Mission Impossible, Bohemian Rhapsody dan Symphony no. 40 (Mozart).

e. Otto Stuparitz (38 tahun) adalah perwakilan dari wisatawan yang dating ke SAU dan ia mengaku tahu tentang tempat ini dari internet. Sebagai seorang yang berprofesi sebagai musikolog, ia mengaku sangat terhibur dengan music bambu. Dalam khazanah musik Barat, bahan bamboo kurang dikenal sehingga bahan bambu memang langsung identik dengan musik Timur.

\section{Berdasarkan Studi Literatur}

Angklung sejak tahun 2010 terdaftar sebagai Intangible Cultural Heritage of Humanity versi UNESCO. Angklung yang dimaksud adalah angklung yang diinovasikan oleh Daeng Sutigna tahun 1938, yang mempunyai laras diatonis. Dalam hal ini, angklung dianggap sebagai bagian dari seni dan kebudayaan orang-orang di Indonesia. Namun jika tidak dilestarikan, maka angklung bisa tergeser dari daftar ini. 


\section{KESIMPULAN}

Berdasarkan hasil dan pembahasan di atas, maka dapat diperoleh kesimpulan sebagai berikut:

1. SAU mempunyai daya tarik berupa dekorasi bambu dan musik bambu yang dijalankan secara edukatif dan atraktif, yang menyentuh pengalaman langsung. Publikasi dan pendokumentasian terkait pertunjukan tersebut terus dilakukan terutama melalui Instagram dan Youtube.

2. Kolaborasi dilakukan untuk menambah popularitas musik bambu, dengan salah satunya menggaet composer Eka Gustiwana. Kolaborasi tersebut me-madukan karya-karya populer yang dimainkan dengan nuansa musik bambu, untuk kemudian diunggah ke Youtube, sehingga menghasilkan karya-karya segar yang aksesibel terhadap publik.

3. Aransemen dilakukan untuk membuat musik bambu familiar terutama di kalangan pendengar musik Barat. Aransemen untuk lagu-lagu seperti Bohemian Rhapsody, Mission Imposible, dan Symphony no. 40 (Mozart) dilakukan dengan harapan dapat diterima lebih banyak kalangan, terutama setelah juga diunggah keYoutube.

4. Penyebaran musik bambu, dalam hal ini secara spesifik angklung, melalui media sosial adalah juga bentuk pelestarian angklung dalam posisinya sebagai Intangible Cultural Heritage of Humanityversi UNESCO yang disahkan tahun 2010. Dengan melakukan penyebaran melalui media sosial, terdapat metadata yang dapat dipertanggungjawaban sebagai bentuk upaya pelestarian.

\section{DAFTAR PUSTAKA}

Alexander, J. C. (2004). Cultural Pragmatics: Social Performance between Ritual and Strategy. Sociological Theory, 22(4), 527-573. doi:10.1111/j.07352751.2004. 00233.x

Budi, E. M., Rochim, A. A., Dipojono, H. K., Handojo, A., \& Sarwono, J. (2013). Musical gesture recognition for interactive angklung robot. 2013 3rd International Conference on Instrumen-tation Control and Automation (ICA). doi:10.1109/ica.2013.6734062

Hani, U., Azzadina, I., Sianipar, C. P. M., Setyagung, E. H., \& Ishii, T. (2012). Preserving Cultural Heritage through Creative Industry: A Lesson from Saung Angklung Udjo. Procedia Economics and Finance, 4, 193-200. doi:10.1016/s2212-5671(12)00334-6

Danim, Sudarwan. (2002). Menjadi Peneliti Kualitatif. Pustaka Setia.

Sugiyono. (2013). Metode Penelitian Pendidikan, Pendekatan Kuantitatif, Kualitatif, dan R\&D. Bandung: Alfabeta.

Sukmadinata, Nana Syaodih. (2012). Metode Penelitian Pendidikan. Bandung: Remaja Rosdakarya. 